\title{
EHMTI-0078. Headache attributed to masticatory myofascial pain: clinical features and management outcomes
}

\author{
YM Costa ${ }^{1 *}$, AL Porporatti $^{1}$, J Stuginski-Barbosa ${ }^{1}$, LR Bonjardim ${ }^{2}$, PCR Conti ${ }^{1}$ \\ From 4th European Headache and Migraine Trust International Congress: EHMTIC 2014 \\ Copenhagen, Denmark. 18-21 September 2014
}

\section{Introduction}

To define better the association between headache and temporomandibular disorders it is important to identify if there is evidence of a headache attributed to temporomandibular disorders.

\section{Aims}

To describe the characteristics of headache attributed to temporomandibular disorders pain and to assess the effect of two management strategies in headache intensity and frequency.

\section{Methods}

The sample $(\mathrm{n}=60)$ of this randomized controlled trial was comprised of masticatory myofascial pain patients, according to the Research Diagnostic Criteria for Temporomandibular Disorders (RDC/TMD) and headache complaints and divided into two groups. The group 1 received only counseling for behavioral changes and the group 2, besides counseling, received occlusal splint. Follow-up was 5 months with three assessments moments. Outcomes were the temporomandibular disorders-related headache characteristics measured by a questionnaire, headache intensity (visual analogue scale - VAS) and frequency (questionnaire). Two-way ANOVA and Chi-Square test were used considering a $5 \%$ significance level.

\section{Results}

The clinical features of headache attributed to temporomandibular disorders were the long duration, fronto-temporal bilateral location and tightening/pressing quality. There was a general reduction in the headache intensity and frequency without differences between groups. The baseline headache intensity mean (SD) was 7.55 (2.24) for the group 1 and 6.52 (1.63) for group 2. Final values were, respectively, 3.13 (2.19) and 2.5 (2.33).

\section{Conclusion}

Long duration, fronto-temporal bilateral location and a tightening/pressure quality are the most distinguished characteristics in headaches secondary to masticatory myofascial pain. Besides, the management of masticatory myofascial pain could be effective in the improvement of headache attributed to temporomandibular disorders.

No conflict of interest.

\section{Authors' details}

${ }^{1}$ Prosthodontics, Bauru School of Dentistry University of São Paulo, Bauru, Brazil. ${ }^{2}$ Biological Sciences, Bauru School of Dentistry University of São Paulo, Bauru, Brazil.

Published: 18 September 2014

doi:10.1186/1129-2377-15-S1-D13

Cite this article as: Costa et al:: EHMTI-0078. Headache attributed to masticatory myofascial pain: clinical features and management outcomes. The Journal of Headache and Pain 2014 15(Suppl 1):D13

'Prosthodontics, Bauru School of Dentistry University of São Paulo, Bauru,

Brazil

Full list of author information is available at the end of the article

C 2014 Costa et al; licensee Springer. This is an Open Access article distributed under the terms of the Creative Commons Attribution License (http://creativecommons.org/licenses/by/2.0), which permits unrestricted use, distribution, and reproduction in any medium, provided the original work is properly cited. 